\title{
Physicochemical Changes of Contaminated Titanium Discs Treated With Erbium-Doped Yttrium Aluminum Garnet (Er:YAG) Laser Irradiation or Air- Flow Abrasion: An In Vitro Study
}

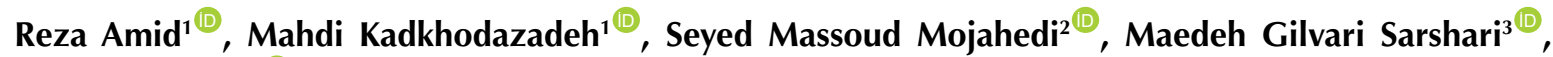 \\ Zeinab Zamani ${ }^{\circledR}$ \\ 'Department of Periodontics, School of Dentistry, Shahid Beheshti University of Medical Sciences, Evin, Tehran, Iran \\ ${ }^{2}$ Department of Laser, School of Dentistry, Shahid Beheshti University of Medical Sciences, Tehran, Iran \\ ${ }^{3}$ Research Institute of Dental Sciences, School of Dentistry, Shahid Beheshti University of Medical Sciences, Tehran, \\ Iran
}

\section{*Correspondence to Zeinab Zamani \\ Dentist, Post graduate student, Research Institute of Dental Sciences, School of Dentistry, Shahid Beheshti University of Medical Sciences, Tehran, Iran. Tel: +989127305245, Email: zeinab_zamani@yahoo. com}

Received: August 6, 2020 Accepted: February 22, 2021 Published online November 6 , 2021

\begin{abstract}
Introduction: Peri-implantitis is a common complication of dental implant treatment. A cause-andeffect relationship has been previously documented between microbial plaque and peri-implantitis and implant failure. A difference has been reported in the disinfection efficacy of erbium laser irradiation and air-flow abrasion for contaminated titanium surfaces. Also, the surface changes caused by lasers and air-flow abrasion have not been well studied. Thus, the purpose of this study was to compare the surface changes of contaminated titanium discs following decontamination by erbium-doped yttrium aluminum garnet (Er:YAG) laser irradiation and air-flow abrasion.

Methods: Twenty-eight intact, sandblasted, and acid-etched (SLA) titanium discs were used. Twentyfour titanium discs were contaminated with Escherichia coli. Then, they were decontaminated by using Er:YAG laser irradiation and air-flow abrasion. Four discs remained intact. The mean and standard deviation of the contact angle and the weight percentage of aluminum, titanium, oxygen, carbon, phosphorus, and calcium were measured. Qualitative changes in surface topography of titanium discs were assessed by scanning electron microscopy (SEM).

Results: The mean weight percentage of carbon in the air-flow abrasion group (4.98\%) experienced a significant reduction compared with the contaminated (positive control) group $(P=0.035)$. The contact angles were $46.54^{\circ}$ and $38.67^{\circ}$ in the laser and air-flow abrasion groups respectively, which were significantly lower than the value in the positive control group $\left(75.15^{\circ}\right)(P \leq 0.001)$. SEM micrographs showed no significant change in the surface area in either technique.

Conclusion: Air-flow abrasion was more successful in improving the surface characteristics of titanium discs with no alteration in surface topography or elements, compared with Er:YAG laser irradiation. Further studies regarding the safety of the Er:YAG laser for the decontamination of titanium surfaces are recommended.

Keywords: Peri-Implantitis; Lasers; Decontamination; Wettability; SEM; Energy Dispersive X-ray Spectroscopy.
\end{abstract}

\section{Introduction}

Peri-implantitis is a common complication of implant treatment, which is characterized by an inflammatory process that affects the soft and hard tissues surrounding the osseointegrated dental implants. Peri-implantitis is caused by the activity of pathogenic bacteria. ${ }^{1,2}$ Spirochetes and Gram-negative anaerobes are the most common bacteria causing peri-implantitis., Therefore, surface debridement is the first step in the treatment of peri-implantitis, ${ }^{5}$ similar to periodontitis. ${ }^{6}$
The decontamination of dental implants is a difficult procedure due to the structure of the implant surface. ${ }^{5,7}$ The conventional methods commonly used for implant surface decontamination include the use of plastic curettes, ultrasonic scalers, and air-flow abrasion. ${ }^{8}$ However, the conventional methods cannot efficiently remove the bacteria from the implant surface due to limited access to the microscopic rough porosities on the implant surface. ${ }^{5,9}$ According to some studies, air-flow abrasion can effectively remove the microbial plaque

Please cite this article as follows: Amid R, Kadkhodazadeh M, Mojahedi SM, Sarshari MG, Zamani Z. Physicochemical changes of contaminated titanium discs treated with erbium-doped yttrium aluminum garnet (Er:YAG) laser irradiation or air-flow abrasion: an in vitro study. J Lasers Med Sci. 2021;12:e67. doi:10.34172/jlms.2021.67. 
from the implant surface. In addition, it has been reported that using sodium bicarbonate or glycine powder is more effective, and it does not cause major damage to the sandblasted and acid-etched titanium implant surfaces. ${ }^{10}$ Nevertheless, the use of glycine powder with a smaller particle size is preferred to sodium bicarbonate due to lower abrasiveness. ${ }^{11,12}$ Another disadvantage of airflow abrasion is its limitation for use in narrow vertical defects. ${ }^{13}$

The Erbium-doped yttrium aluminum garnet (Er:YAG) laser has also been studied for the treatment of periimplantitis. ${ }^{6}$ The Er:YAG laser exerts a high antimicrobial effect on rough implant surfaces without causing significant morphological alternations, and it does not cause a temperature rise over $47^{\circ} \mathrm{C} .{ }^{6,14}$

The implant surface characteristics, such as roughness, composition, wettability, and titanium surface morphology can greatly affect cellular behavior. Data concerning the effect of the Er:YAG laser on the biological properties of titanium surfaces are conflicting. ${ }^{5}$ Also, no standard recommendation exists regarding the type of laser, setting, or irradiation protocol for peri-implantitis treatment. ${ }^{15}$

According to the literature, no gold standard exists for the treatment of peri-implantitis, and the currently practiced modalities cannot ideally eliminate the inflamed tissue, debride the bone defects, or decontaminate the implant surfaces. ${ }^{16}$ Also, limited, yet controversial information, is available regarding the surface changes caused by Er:YAG laser irradiation or air-flow abrasion. Therefore, the purpose of this study was to assess the physicochemical changes of contaminated sandblasted titanium discs treated with Er:YAG laser irradiation or air-flow abrasion.

\section{Materials and Methods \\ Titanium Discs}

Twenty-eight intact, sandblasted, and acid-etched (SLA) titanium discs (Servo-Dental, Germany), measuring 8 $\mathrm{mm}$ in diameter and $2 \mathrm{~mm}$ in thickness, were used in this experimental study. At each step of the experiment, UVexposed containers were used to store the samples.

\section{Contaminating the Discs}

Escherichia coli (ATCC 25922) was cultured in $10 \mathrm{~mL}$ of Todd Hewitt broth to prepare a bacterial suspension with 0.5 McFarland standard concentration with an optical density of $625 \mathrm{~nm}$ containing $1.5 \times 10^{8}$ colony forming units (CFUs)/mL.

Twenty-four titanium discs were inoculated with $E$. coli suspension under aerobic conditions at $37^{\circ} \mathrm{C}$ for 24 hours. After completion of the incubation period, all 24 discs and 4 intact discs were randomly divided into two control (i.e. positive control and negative control) groups and two experimental groups (i.e. laser treatment group and air-flow abrasion group).

\section{Laser Treatment}

The Er:YAGlaser (DEKA, Italy) with a $2940 \mathrm{~nm}$ wavelength and an MZ6 tip was used in this study with $150 \mathrm{~mJ} /$ pulse $(1.5 \mathrm{~W})$ energy density and $10 \mathrm{~Hz}$ frequency. Ten intact discs were randomly chosen for laser treatment. The discs were fixed by forceps, and the laser was irradiated with a sweeping motion from the top to the bottom and from the right to the left side for 30 seconds at $21^{\circ} \mathrm{C}$. The laser beam was pointed to the disc surface using a non-contact tip from a $10 \mathrm{~mm}$ distance. The water flow rate was $50 \%$. After laser treatment, the samples were transferred to a suspension of hydrogen peroxide and silver salt (Nanosile water, Kimia Faam Pharmaceutical Co., Iran) for 90 seconds. Then, they were placed in a container, which had already been exposed to UV radiation for 20 minutes. All procedures were performed by an expert clinician.

\section{Air-Flow Abrasion}

Ten intact discs were treated with an air-polishing device (Perio-Mate, NSK, Japan) and Perio-glycine powder (Perio-Mate, NSK, Japan). The nozzle tip was maintained at a distance of 2-5 $\mathrm{mm}$ from the fixed disc surface, and the disc surface was treated with sweeping motions from the top to the bottom and from the right to the left side for 30 seconds at $21^{\circ} \mathrm{C}$. Afterwards, they were immersed in a suspension of hydrogen peroxide and silver salt (Nanosile water, Kimia Faam Pharmaceutical Co., Iran) for 90 seconds. Finally, they were placed in a container, which had already been exposed to UV radiation for 20 minutes. All procedures were performed by an expert clinician.

\section{Surface Wettability Measurement}

The wettability of the experimental disc surfaces was determined according to their contact angle. The contact angle of the disc surfaces was measured using CA-ES20 (Fars EOR Technologies CO, Iran). The contact angle was measured three times for each sample. Distilled water $\left(1 \mathrm{~g} / \mathrm{cm}^{2}\right)$ was added on the disc surface at $21^{\circ} \mathrm{C}$ using a needle with $0.793 \mathrm{~mm}$ diameter, and it was photographed immediately.

\section{Energy Dispersive X-ray Spectroscopy}

Elemental analysis of the treated surfaces was carried out using an energy dispersive X-ray micro-analyzer (Roentec Detector, Roentec ${ }^{\odot}$, Berlin, Germany). The phosphorus, carbon, oxygen, aluminum, calcium, and titanium contents of the surfaces were quantified in the experimental groups as such.

\section{Scanning Electron Microscopy}

The surface alterations of each experimental disc were evaluated using scanning electron microscopy (SEM). The discs were gold coated and observed under a scanning 
electron microscope (TeScan-Mira III, Czech) at $\times 1000$, $\times 5000, \times 25000$, and $\times 50000$ magnifications). Random SEM micrographs were also obtained to evaluate the morphological and topographic changes of SLA surfaces such as glossiness, melting, ripple patterns, cracking, and slip line formation. ${ }^{17}$

\section{Statistical Analysis}

The sample size was determined according to the studies by Ayobian-Markazi et $\mathrm{al}^{5}$ and Giannini et al ${ }^{18}$ (Figure 1). The mean and standard deviation of weight percentages of aluminum, titanium, oxygen, carbon, phosphorus, and calcium in the experimental groups were analyzed using the Kruskal-Wallis test. The Dunn-Q Bonferroni test was employed to compare the study groups. Moreover, the mean contact angle was analyzed using the one-way analysis of variance (ANOVA, Welch) robust equivalent test, and the Games-Howell post hoc test was used to compare the experimental groups. All statistical analyses were carried out using SPSS version 24.0.

\section{Results}

\section{Surface Wettability Measurement}

As shown in Table 1, the mean contact angle in the negative control group was larger than that in the experimental groups and the positive control group. Moreover, the results of the Games-Howell test (Table 2) indicated no significant difference in the contact angle between the airflow abrasion and erbium laser groups $(P=0.176)$.

\section{Results of Energy Dispersive X-ray Spectroscopy}

The results of the non-parametric Kruskal-Wallis test demonstrated a significant difference between the weight percentages of the main elements of disc surfaces. The results of the Dunn-Q Bonferroni test revealed a significant difference in the percentage of phosphorus between the air-flow abrasion and Er:YAG laser groups $(P=0.014)$ and also between the air-flow abrasion and negative control groups $(P=0.004)$. Moreover, significant differences were
Table 1. Comparison of Contact Angle (in Degrees) Between the Four Groups of Air-Flow Abrasion, Er:YAG Laser, Negative Control, and Positive Control

\begin{tabular}{lccc}
\hline \multirow{2}{*}{ Group } & \multicolumn{3}{c}{ Contact Angle } \\
\cline { 2 - 4 } & Mean & Minimum & Maximum \\
\hline Air-flow abrasion & $38.67 \pm 14.26$ & 15.78 & 67.412 \\
Er:YAG laser & $46.54 \pm 12.98$ & 18.28 & 72.31 \\
Negative control & $83.52 \pm 0.85$ & 82.57 & 84.21 \\
Positive control & $75.15 \pm 22.2$ & 34.9 & 114.4 \\
$P$ value & 0.0001 & - & - \\
\hline
\end{tabular}

Table 2. Pairwise Comparisons of the Contact Angle (in Degrees) Between the Four Groups of Air-Flow Abrasion, Er:YAG Laser, Negative Control, and Positive Control

\begin{tabular}{|c|c|c|c|}
\hline & (I) Group & (J) Group & $P$ Value \\
\hline \multirow{12}{*}{ Games-Howell } & \multirow{3}{*}{ Air-Flow } & Erbium & 0.176 \\
\hline & & Negative control & 0.000 \\
\hline & & Positive control & 0.000 \\
\hline & \multirow{4}{*}{ Erbium } & Air-flow & 0.176 \\
\hline & & Negative control & 0.000 \\
\hline & & Positive control & 0.000 \\
\hline & & Air-flow & 0.000 \\
\hline & \multirow[t]{2}{*}{ Negative control } & Erbium & 0.000 \\
\hline & & Positive control & 0.248 \\
\hline & \multirow{3}{*}{ Positive control } & Air-flow & 0.000 \\
\hline & & Erbium & 0.000 \\
\hline & & Negative control & 0.248 \\
\hline
\end{tabular}

noted in carbon and titanium percentages between the air-flow abrasion and positive control groups $(P=0.035$ for carbon and $P=0.048$ for titanium) and also between the negative and positive control groups $(P=0.016$ for carbon and $P=0.029$ for titanium).

The comparison between the Er:YAG and positive control groups demonstrated a significant difference in calcium content $(P=0.005)$. Although the carbon percentage in the air-flow treated group was slightly

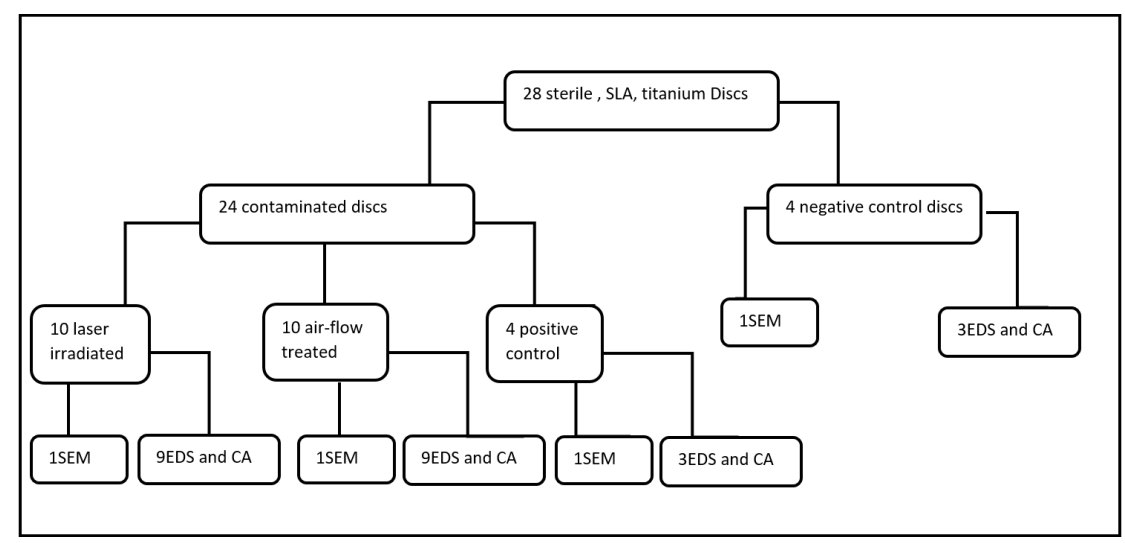

Figure 1. The Number of Samples Used at Each Stage of the Study. 
lower than that in the laser group, this difference was not statistically significant. The mean weight percentage of oxygen was minimum in the negative control group and maximum in the positive control group. A comparison of laser and air-flow abrasion groups revealed that the mean percentage of oxygen was lower in the air-flow abrasion group by approximately 5.16 units. However, this difference was not significant $(P=0.291)$ (Table 3, Figure 2).

\section{Scanning Electron Microscopy}

At $\times 1000$ to $\times 25000$ magnifications, the highest level of similarity was observed between the surface of negative control discs and air-flow treated discs (Figure 3). No significant difference was found between the laserirradiated and air-flow treated disc surfaces.

\section{Discussion}

The chemical composition and the titanium implant surface charge may vary depending on implant's mass composition and type of surface treatment. Chemical composition and electric charge of the surface are two important factors determining protein absorption and cell adhesion to surfaces. The hydrophilicity of the surface is determined by the chemical composition of titanium implant surfaces. The surfaces that are highly hydrophilic are apparently more favorable than hydrophobic surfaces and better interact with cells, biological fluids, and tissues. ${ }^{19}$ Surface wettability, which largely depends on surface free energy, has a fundamental role in host tissue cell healing and regeneration. It also enables the implant surface interactions with the biological environment. ${ }^{20}$ Furthermore, it enhances cellular adhesion, protein adsorption, and spreading. ${ }^{21}$ Topographic parameters such as micro-texture and roughness and surface chemistry also affect wettability. ${ }^{20}$ Borgs et al indicated a reduction in roughness in surface contact angles $<90^{\circ}$ and an increase in roughness when the contact angle was greater than $90^{\circ} .{ }^{22}$ In the present study, the mean contact angle in both laser-treated and air-flow abrasion groups was significantly smaller than that in the negative control group. This result indicates the success of both treatments in increasing the titanium surface wettability. The difference in the mean contact angle was not significant between the laser and air-flow abrasion groups. However, the mean contact angle was smaller in the air-flow abrasion group $(P=0.176)$. Strever et al aimed to develop a laboratory model of single-species biofilm on implant surfaces and find ideal Er,Cr:YSGG laser power settings to remove the biofilm without damaging the surface.

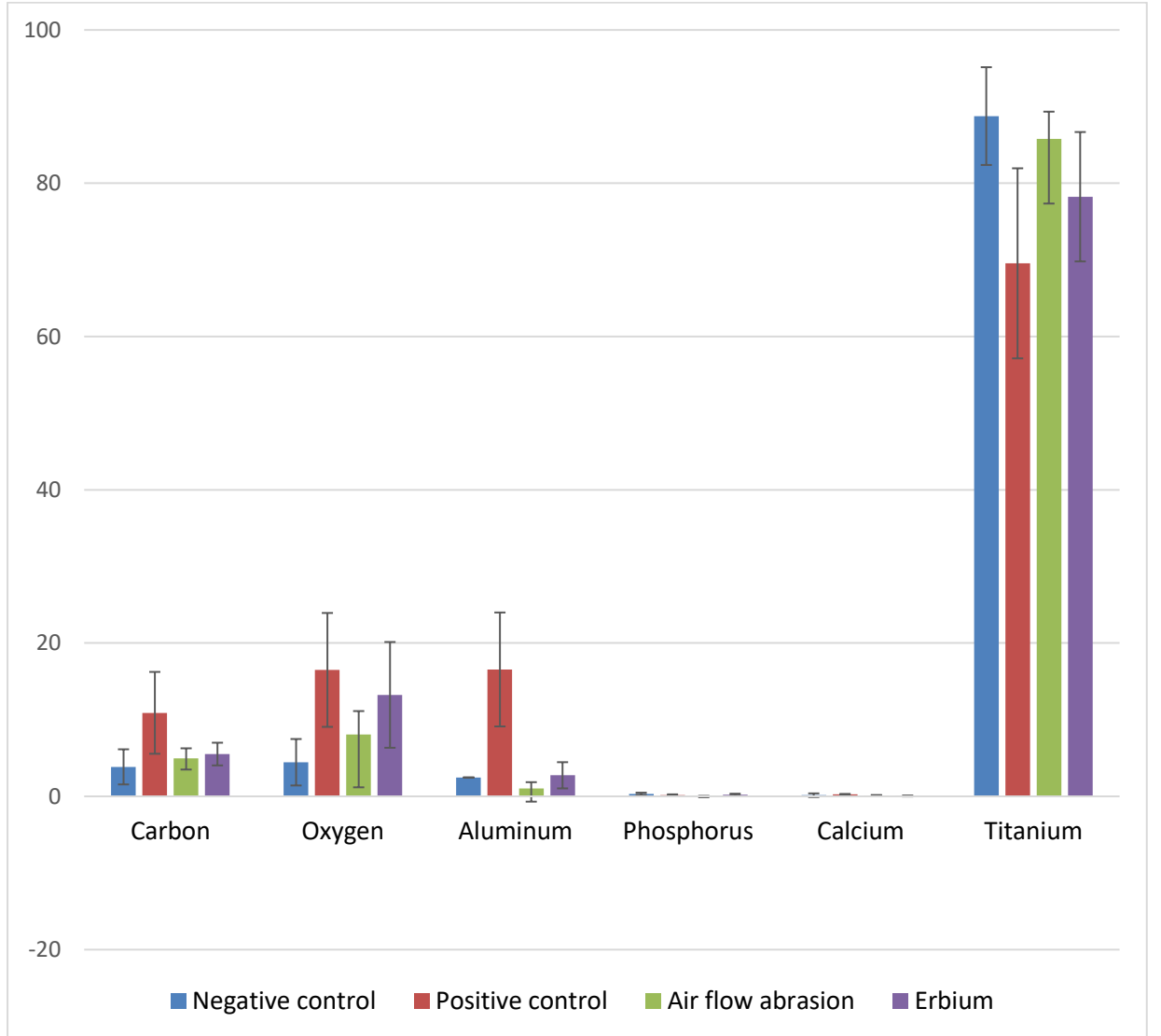

Figure 2. Comparison of the Weight Percentage of the Main Elements of the Disc Surfaces Between the Four Groups of Air-Flow Abrasion, Er:YAG Laser, Negative Control Group, and Positive Control Group. 
Table 3. Comparison of the Weight Percentage of the Main Elements of the Disc Surfaces Between the Four Groups of Air-Flow Abrasion, Er:YAG Laser, Negative Control, and Positive Control

\begin{tabular}{lcccccccc}
\hline \multirow{2}{*}{ Group } & \multicolumn{9}{c}{ Element } & & & \\
\cline { 2 - 7 } & Carbon & Oxygen & Aluminum & Phosphorus & Calcium & Titanium & Total \\
\hline Negative control & $3.85 \pm 2.29$ & $4.45 \pm 3.03$ & $2.46 \pm 0.03$ & $0.33 \pm 0.15$ & $0.15 \pm 0.24$ & $88.76 \pm 6.38$ & $112.2 \pm 1.7$ \\
Positive control & $10.9 \pm 5.34$ & $16.56 \pm 7.43$ & $2.57 \pm 1.11$ & $0.17 \pm 0.09$ & $0.24 \pm 0.08$ & $69.55 \pm 12.4$ & $111 \pm 1.1$ \\
Air flow abrasion & $4.98 \pm 1.29$ & $8.08 \pm 3.05$ & $1.02 \pm 0.83$ & $0.02 \pm 0.04$ & $0.1 \pm 0.07$ & $85.79 \pm 3.55$ & $107.94 \pm 2.35$ \\
Erbium & $5.52 \pm 1.48$ & $13.24 \pm 6.9$ & $2.75 \pm 1.71$ & $0.22 \pm 0.13$ & $0.05 \pm 0.06$ & $78.24 \pm 8.44$ & $109.7 \pm 2.52$ \\
$P$ value & 0.015 & 0.014 & 0.02 & 0.002 & 0.007 & 0.006 & 0.038 \\
\hline
\end{tabular}

A single-species biofilm containing Porphyromonas gingivalis was formed on the surface of titanium discs. The Er,Cr:YSGG laser was applied with $0 \mathrm{~W}, 0.5 \mathrm{~W}, 1.0 \mathrm{~W}$, and $1.5 \mathrm{~W}$ power with a radial firing tip. No permanent or repairable change in the contact angle of water was noted as a result of laser treatment on any surface. ${ }^{23}$

In the present study, significant differences were noted in weight percentages of all elements between the groups; thus, the null hypothesis was rejected. the mean weight percentage of calcium in the laser-treated group was significantly lower than that in the positive control group $(P=0.005)$. Also, calcium had the highest percentage $(0.24 \% \pm 0.08 \%)$ in the positive control group compared with other groups, which may indicate the presence of
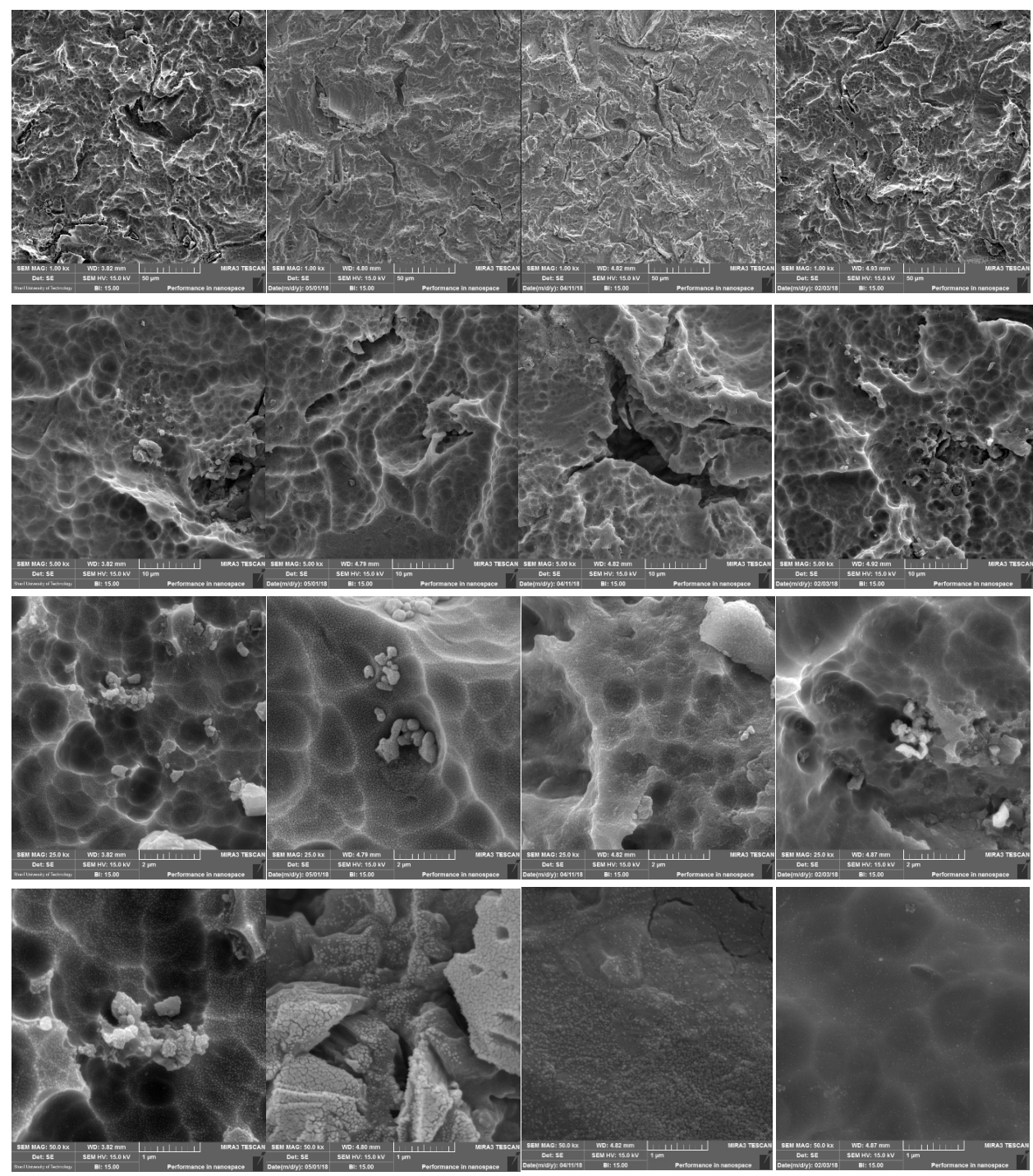

Figure 3. SEM View for different titanium disc surface are shown in rows from left to right including: Negative control, Positive control, Air flow abrasion, Erbium and different magnification levels are shown in columns from top to bottom including: $\times 1000, \times 5000, \times 25000, \times 50000$. 
organic contaminants on the positive control discs and the success of the Er:YAG laser was in the decontamination of the discs. The amount of calcium was lower in laserirradiated discs in comparison with air-flow treated discs, but not significantly.

The mean weight percentage of carbon in the positive control group was the highest, probably due to its high organic content. However, the percentage of carbon was the lowest in the negative control group. The difference in the mean weight percentage of carbon was significant between the two groups $(P=0.016)$. Moreover, the significant reduction in the mean weight percentage of carbon in air-flow treated and laser-treated groups suggests a probable reduction in surface contamination with hydrocarbons, although the percentage of carbon in the air-flow abrasion group was slightly, but not significantly, lower than that in the Er:YAG group. This result indicates the absence of carbonation and harmful side effects of the Er:YAG laser at a $2940 \mathrm{~nm}$ wavelength and $150 \mathrm{~mJ} /$ pulse energy to create a carbon layer on the surface of SLA discs.

Taniguchi et al showed that the use of laser beam with water spray decreased the carbon and oxygen contents, which indicates that the Er:YAG laser can successfully remove hydrocarbons (which prevent osseointegration). However, without the use of water spray, laser radiation can increase the oxygen content. This finding indicates the oxidation of the implant surface due to a temperature rise during calculus removal. ${ }^{13}$ An increase in the oxygen content of the Er:YAG laser group, compared with the negative control group in our study, is probably due to the interference of the laser with water, although this increase was not statistically significant.

A comparison of the mean weight percentage of titanium between the positive control group and the airflow abrasion group revealed a statistically significant difference $(P=0.048)$. The mean weight percentage of titanium was lower by about 16.24 units in the positive control group, compared with the air-flow abrasion group. Although the content of oxygen and titanium in the airflow abrasion group was most similar to the negative control group, further studies are needed to study the changes in the thickness of the $\mathrm{TiO}_{2}$ layer.

Similar to a review study by Tastepe et al, SEM micrographs of surfaces treated by air-flow abrasion in the present study were similar to those of the negative control surfaces. $^{24}$ Stübinger et al used an Er:YAG laser with 10 $\mathrm{Hz}$ frequency and 100, 300, 500, and $1000 \mathrm{~mJ}$ energy densities. The SLA surfaces did not demonstrate any change following laser irradiation with energy densities below $300 \mathrm{~mJ}$. The disc surfaces did not change prior to Er:YAG laser irradiation by $500 \mathrm{~mJ}$ energy and $10 \mathrm{~Hz}$ frequency. However, following laser irradiation with 500 $\mathrm{mJ}$ energy and $10 \mathrm{~Hz}$ frequency, the cracks started to form at $\times 1600$ magnification. ${ }^{25}$ In a study by Kim et al, Osseotite implants were exposed to 1, 1.5 and 2 minutes of Er:YAG laser irradiation with 100,140, and $180 \mathrm{~mJ} /$ pulse energy density and $10 \mathrm{~Hz}$ frequency. No considerable change was observed after 2 minutes of laser irradiation with $100 \mathrm{~mJ}$ energy and $10 \mathrm{~Hz}$ frequency. Moreover, no melting or cracking occurred in any of the samples in laser energies lower than $180 \mathrm{~mJ}{ }^{26}$

In a study by Taniguchi et al, five commercial implants (Osseotite $^{\circledast}$, Tioblast ${ }^{\circledast}$, TiUnite ${ }^{\oplus}, \mathrm{RBM}^{\oplus}, \mathrm{SLA}^{\oplus}$ ) were subjected to an Er:YAG laser. The laser was irradiated on each micro-structured surface in near-contact mode from $1 \mathrm{~mm}$ by a contact tip. At each radiation spot, the Er:YAG laser was irradiated for $5 \mathrm{~s}$ with 30,40 , and $50 \mathrm{~mJ} /$ pulse energy and $30 \mathrm{~Hz}$ frequency under water spray and $50 \mathrm{~mJ} /$ pulse energy without water spray. SEM indicated that $40 \mathrm{~mJ}$ laser irradiation under water coolant caused partial melting of the micro-structural edges of SLA ${ }^{\oplus}$ and $\mathrm{RBM}^{\circledR}$ surfaces. With $50 \mathrm{~mJ}$ irradiation with water spray, all surfaces melted except for Osseotite ${ }^{\circledR}$. However, $50 \mathrm{~mJ}$ radiation without water spray created severe morphological changes on all surfaces. The TiUnite implant degraded in the use of all levels of laser energy, even with water spray. ${ }^{13}$ Their study emphasized the important role of implant type or titanium disc in surface changes caused by laser irradiation.

Although Actinobacillus actinomycetemcomitans is a common microorganism associated with peri-implantitis, it requires a microaerophilic atmosphere. ${ }^{18}$ Thus, in the present study, E. coli as a Gram-negative aerobe was used, which can be considered as a limitation of this study. In addition, the internal pigments of black-pigmented species absorb red light and subsequently improve the laser efficacy. ${ }^{17}$

Since it is not possible to stabilize the distance of the laser beam from the implant surface in clinical conditions, we used an experienced clinician in this study to approximate this distance. Also, in most clinical protocols, the use of chemical methods such as rinsing with chlorhexidine or hydrogen peroxide is common as an adjunct; thus, hydrogen peroxide rinsing was performed equally for all discs in this study for better simulation of intraoral conditions.

According to Schwarz et al., the irradiation of the Er:YAG laser (100 mJ/pulse, $10 \mathrm{~Hz}, 60$ seconds) was more efficacious than plastic curettes for microbial biofilm removal from the SLA surfaces and did not cause surface changes. ${ }^{27}$ Shin et al showed surface changes following the use of all different setting times with $180 \mathrm{~mJ} /$ pulse laser irradiation. ${ }^{28}$ In the present study, we used the Er:YAG laser (DEKA, Italy) with a $2940 \mathrm{~nm}$ wavelength and an MZ6 tip with $150 \mathrm{~mJ} /$ pulse energy $(1.5 \mathrm{~W})$ and $10 \mathrm{~Hz}$ frequency for 30 seconds.

\section{Conclusion}

According to the results, the mean weight percentage of 
surface elements following air-flow abrasion was more similar to that in the negative control discs. Moreover, surface contamination with carbon was low in the air-flow abrasion group, while the oxygen content was greater in the Er:YAG laser group. However, these differences were not statistically significant. The contact angle similarly and significantly decreased in both surface decontamination methods. Furthermore, according to SEM micrographs, the laser-irradiated and air-flow treated surfaces had no significant difference.

\section{Ethical Considerations}

This study has been approved by research institute of dental sciences, Shahid Beheshti University of Medical Sciences, Tehran, Iran.

\section{Conflict of Interests}

The authors declare that they have no conflict of interest.

\section{References}

1. Mahato N, Wu X, Wang L. Management of peri-implantitis: a systematic review, 2010-2015. Springerplus. 2016; 5:105. doi:10.1186/s40064-016-1735-2.

2. Faveri M, Figueiredo LC, Shibli JA, Pérez-Chaparro PJ, Feres M. Microbiological diversity of peri-implantitis biofilms. Adv Exp Med Biol. 2015; 830:85-96. doi:10.1007/978-3319-11038-7_5.

3. Mombelli A. Etiology, diagnosis, and treatment considerations in Peri-Implantitis. Curr opin Periodontol. 1997; 4:127-36.

4. Mombelli A, Décaillet F. The characteristics of biofilms in peri-implant disease. J Clin Periodontol. 2011;38(S11):20313. doi:10.1111/j.1600-051X.2010.01666.x.

5. Ayobian-Markazi N, Karimi M, Safar-Hajhosseini A. Effects of Er: YAG laser irradiation on wettability, surface roughness, and biocompatibility of SLA titanium surfaces: an in vitro study. Laser Med Sci. 2015;30(2):561-6. doi:10.1007/s10103-013-1361-y.

6. Persson GR, Roos-Jansåker AM, Lindahl C, Renvert S. Microbiologic results after non-surgical erbium-doped: yttrium, aluminum, and garnet laser or air-abrasive treatment of peri-implantitis: a randomized clinical trial. J Periodontol. 2011;82(9):1267-78. doi:10.1902/ jop.2011.100660

7. Schwarz F, Sculean A, Romanos G, Herten M, Horn N, Scherbaum W, et al. Influence of different treatment approaches on the removal of early plaque biofilms and the viability of SAOS2 osteoblasts grown on titanium implants. Clin Oral Investig. 2005;9(2):111-7. Doi:10.1007/s00784005-0305-8.

8. Fox SC, Moriarty JD, Kusy RP. The effects of scaling a titanium implant surface with metal and plastic instruments: an in vitro study. J Periodontol. 1990;61(8):48590. doi:10.1902/jop.1990.61.8.485.

9. Jayachandran Prathapachandran NS. Management of PeriImplantitis. Dent Res J (Isfahan). 2012;9(5):516-21. doi: 10.4103/1735-3327.104867.

10. Schwarz F, Becker K, Renvert S. Efficacy of air polishing for the non-surgical treatment of peri-implant diseases: a systematic review. J Clin Periodontol. 2015;42(10):951-9. doi:10.1111/jcpe.12454.

11. Petersilka G, Faggion Jr CM, Stratmann U, Gerss J, Ehmke B, Haeberlein I, et al. Effect of glycine powder air-polishing on the gingiva. J Clin Periodontol. 2008;35(4):324-32. doi:10.1111/j.1600-051X.2007.01195.x.

12. Schwarz F, Ferrari D, Popovski K, Hartig B, Becker J. Influence of different air-abrasive powders on cell viability at biologically contaminated titanium dental implants surfaces. J Biomed Mater Res B Appl Biomater. 2009;88(1):83-91. doi:10.1002/jbm.b.31154.

13. Taniguchi Y, Aoki A, Mizutani K, Takeuchi Y, Ichinose S, Takasaki AA, et al. Optimal Er: YAG laser irradiation parameters for debridement of microstructured fixture surfaces of titanium dental implants. Laser Med Sci. 2013;28(4):1057-68. doi:10.1007/s10103-012-1171-7.

14. Kreisler M, Kohnen W, Christoffers AB, Götz H, Jansen B, Duschner $\mathrm{H}$, et al. In vitro evaluation of the biocompatibility of positive control implant surfaces treated with an Er: YAG laser and an air powder system. Clin Oral Implants Res. 2005;16(1):36-43. doi:10.1111/j.1600-0501.2004.01056.x.

15. Kamel MS, Khosa A, Tawse-Smith A, Leichter J. The use of laser therapy for dental implant surface decontamination: a narrative review of in vitro studies. Laser Med Sci. 2014;29(6):1977-85. doi:10.1007/s10103-013-1396-0.

16. Schwarz F, John G, Mainusch S, Sahm N, Becker J. Combined surgical therapy of peri-implantitis evaluating two methods of surface debridement and decontamination. A two-year clinical follow up report. J Clin Periodontol. 2012;39(8):789-97. doi:10.1111/j.1600-051X.2012.01867.x.

17. Saffarpour A, Nozari A, Fekrazad R, Saffarpour A, Heibati MN, Iranparvar K. Microstructural Evaluation of Contaminated Implant Surface Treated by Laser, Photodynamic Therapy, and Chlorhexidine 2\%. Int J Oral Maxillofac Implants. 2018;33(5): 1019-1026.doi:10.11607/ jomi.6325.

18. Giannini R, Vassalli M, Chellini F, Polidori L, Dei R, Giannelli M. Neodymium: yttrium aluminum garnet laser irradiation with low pulse energy: a potential tool for the treatment of peri-implant disease. Clin Oral Implants Res. 2006;17(6):638-43.doi:10.1111/j.1600-0501.2006.01278.x.

19. Le Guéhennec L, Soueidan A, Layrolle P, Amouriq Y. Surface treatments of titanium dental implants for rapid osseointegration. Dent Mater. 2007; 23(7):844-54. doi:10.1016/j.dental.2006.06.025.

20. Zhu X, Chen J, Scheideler L, Reichl R, Geis-Gerstorfer J. Effects of topography and composition of titanium surface oxides on osteoblast responses. Biomaterials. 2004; 25(18):4087-103. doi:10.1016/j.biomaterials.2003.11.011.

21. Van Kooten TG, Schakenraad JM, van der Mei HC, Busscher HJ. Influence of substratum wettability on the strength of adhesion of human fibroblasts. Biomaterials. 1992;13(13):897-904. doi:10.1016/0142-9612(92)90112-2.

22. Borgs C, De Coninck J, Kotecký R, Zinque M. Does the roughness of the substrate enhance wetting?. Phys Rev Lett. 1995;74(12):2292-2294. doi:10.1103/PhysRevLett.74.2292.

23. Strever JM, Lee J, Ealick W, Peacock M, Shelby D, Susin C, et al. Erbium, Chromium: Yttrium-Scandium- 
Gallium-Garnet Laser Effectively Ablates Single-Species Biofilms on Titanium Disks Without Detectable Surface Damage. J Periodontol. 2017;88(5):484-92. doi:10.1902/ jop.2016.160529.

24. Tastepe CS, van Waas R, Liu Y, Wismeijer D. Air powder abrasive treatment as an implant surface cleaning method: a literature review. Int J Oral Maxillofac Implants. 2012;27(6):1461-73.

25. Stübinger S, Etter C, Miskiewicz M, Homann F, Saldamli B, Wieland M, et al. Surface alterations of polished and sandblasted and acid-etched titanium implants after Er: YAG, carbon dioxide, and diode laser irradiation. Int J Oral Maxillofac Implants. 2010; 25(1):104-11.

26. Kim J-H, Herr Y, Chung J-H, Shin S-I, Kwon Y-H. The effect of erbium-doped: yttrium, aluminium and garnet laser irradiation on the surface microstructure and roughness of double acid-etched implants. J Periodontal Implant Sci. 2011; 41(5):234-41. doi:10.5051/jpis.2011.41.5.234.

27. Schwarz F, Rothamel D, Sculean A, Georg T, Scherbaum W, Becker J. Effects of an Er: YAG laser and the Vector ${ }^{\circ}$ ultrasonic system on the biocompatibility of titanium implants in cultures of human osteoblast-like cells. Clin. Oral Implants Res. 2003;14(6):784-92. doi:10.1046/j.09057161.2003.00954.x.

28. Shin SI, Min HK, Park BH, Kwon YH, Park JB, Herr Y, Heo SJ, Chung JH. The effect of Er: YAG laser irradiation on the scanning electron microscopic structure and surface roughness of various implant surfaces: an in vitro study. Laser Med Sci. 2011; 26(6):767-76. doi:10.1007/s10103010-0819-4. 